\title{
PENGEMBANGAN SISTEM INFORMASI TERPADU FMIPA UNIVERSITAS LAMPUNG (SIMIPA) MENGGUNAKAN METODE SCRUME
}

\author{
Ardiansyah $^{1}$, Fuad Yudhi Yahya ${ }^{2}$, Anie Rose Irawati ${ }^{3}$, Machudor Yusman ${ }^{4}$ \\ ${ }^{1223}$ Jurusan Ilmu Komputer, Fakultas Matematika dan Ilmu Pengetahuan Alam Universitas Lampung Bandar \\ Lampung
}

Jl. Prof. Dr. Ir. Sumantri Brojonegoro, Gedong Meneng, Kec. Rajabasa, Kota Bandar Lampung, Lampung 35141, Indonesia

Email :ardiansyah@fmipa.unila.ac.idl , fuadyahya1812@gmail.com ${ }^{2}$,an.irawati@gmail.com³, machudoryusman@yahoo.com ${ }^{4}$

\begin{abstract}
SIMIPA is an integrated information system for the faculty of mathematics and natural sciences based on a website that functions as a system that can provide services for students and lecturers in the faculty scope. SIMIPA development is based on a pre-existing system. SIMIPA's business process is centered on service form administration, where in its application there are still several problems that must be resolved using the system. One of them is making service forms which are still done manually and student data is not stored in the database, so students must fill in their personal data repeatedly every time they submit a form. The purpose of developing SIMIPA is to add some features needed as well as management of student data in SIMIPA to make it easier for students to get services. This system was developed using the Scrum method which consists of 23 product backlogs with 7 iterations of sprint stages with development targets for 67 days of work.
\end{abstract}

Keyword : Information systems, academic services, scrum, agile.

\begin{abstract}
Abstrak
SIMIPA merupakan Sistem Informasi Terpadu Fakultas Matematika dan Ilmu Pengetahuan Alam berbasis website yang berfungsi sebagai sistem yang dapat memberikan pelayanan bagi mahasiswa/i maupun dosen di ruang lingkup fakultas. Pengembangan SIMIPA dilakukan berdasarkan sistem yang sudah ada sebelumnya. Proses bisnis SIMIPA berpusat pada administrasi form layanan, dimana dalam penerapannya masih ada beberapa permasalahan yang harus diselesaikan menggunakan sistem. Salah satunya adalah pembuatan form layanan yang masih dilakukan secara manual serta data mahasiswa tidak tersimpan di database, sehingga mahasiswa harus mengisi data diri secara berulang setiap akan mengajukan formulir. Tujuan dari penegembangan SIMIPA adalah menambahkan beberapa fitur yang dibutuhkan serta pengelolaan data mahasiswa yang ada didalam SIMIPA untuk mempermudah mahasiswa/i dalam mendapatkan pelayanan. Sistem ini dikembangkan menggunakan metode scrum yang terdiri dari 23 product backlog dengan tahapan sprint sebanyak 7 iterasi dengan terget pengembangan selama 64 hari pengerjaan.
\end{abstract}

Kata Kunci : Sistem informasi, layanan akademik, scrum, agile.

\section{Pendahuluan}

Kebutuhan konsep dan mekanisme suatu pelayanan berbasis teknologi informasi menjadi suatu kebutuhan yang banyak digunakan pada instansi akademik maupun non-akademik. Salah satunya adalah Sistem informasi terpadu FMIPA yang merupakan sistem informasi berbasis website yang dikelola oleh Fakultas Matematika dan Ilmu Pengetahuan Alam Universitas Lampung dan berfungsi sebagai sistem yang dapat memberikan pelayanan bagi mahasiswa/i maupun dosen di ruang lingkup fakultas.
Saat ini sistem pelayanan yang ada di website FMIPA terutama bagian pelayanan pengajuan formulir surat dari mahasiswa maupun dosen ke dekanat masih dilakukan dengan cara sistem unduh manual yang artinya mahasiswa atau dosen yang mengajukan formulir ke dekanat harus mengunduh formulir yang dikehendaki dan mengubah isi surat secara manual menggunakan software pengolah kata. Kemudian surat yang tercetak diserahkan kembali ke loket adminstrasi dekanat. Formulir yang telah diajukan tidak dapat dilihat proses tracking secara real time keberadaanya sehingga membuat mahasiswa atau dosen yang mengajukan formulir 
tersebut harus mengecek secara langsung ke loket pengambilan dokumen. Hal ini sering dianggap kurang efisien karena dapat memakan waktu apalagi ditambah dengan kesibukan belajar mengajar di kelas. Disisi lain data mahasiswa yang mengajukan formulir belum tersimpan dalam sistem secara efektif dan efisien. Selain itu ada beberapa fitur yang belum ada pada Sistem Informasi Terpadu FMIPA Universitas Lampung antara lain fitur layanan mahasiswa dan staf administrasi fakultas, fitur perkuliahan mahasiswa dan dosen, fitur pengabdian dosen, serta fitur publikasi dosen. Berdasarkan latar belakang tersebut perlu dilakukan pengembangan dalam Sistem Informasi Terpadu FMIPA.

Metode yang digunakan dalam penelitian ini adalah metode scrum, Metode scrum merupakan salah satu metode pengembangan sistem yang bertumpu pada kekuatan kolaborasi tim. Metode scrum dipilih karena dalam pengembangan Sistem Informasi Terpadu FMIPA terbagi menjadi 2 (dua) tim berbeda yaitu tim pengembangan Sistem Informasi Terpadu FMIPA berbasis website dan tim pengembangan aplikasi SIMPA berbasis Android. Kedua sistem tersebut saling terintegrasi satu sama lain dalam beberapa fitur. Metode ini juga dipilih karena metode scrum dianggap mampu mengatasi masalah-masalah yang kompleks dalam pengembangan sistem serta memprioritaskan tugastugas individu, lalu mendelegasikan tugas-tugas tersebut kepada anggota tim yang dianggap sesuai untuk menyelesaikan tugas tersebut.

Berdasarkan latar belakang permasalahan yang sudah dipaparkan maka perlu adanya pengembangan beberapa fitur pada Sistem Informasi Terpadu FMIPA berbasis website dengan menerapkan metode scrum. Pengembangan sistem infomasi ini diharapkan dapat membantu pekerjaan dan proses perkuliahan agar lebih efektif dan efisien.

\section{Studi Literatur}

\section{Sistem Informasi}

Menurut Jogiyanto [1] Sistem Informasi dapat didefinisikan sebagai hasil dari pengolahan data dalam suatu bentuk yang lebih berguna dan lebih berarti bagi penerimanya yang menggambarkan suatu kejadian-kejadian (event) yang nyata (fact) yang digunakan untuk pengambilan keputusan.

\section{Website}

Menurut Kadir [2] Website adalah kumpulan dari halaman web yang menampilkan informasi data teks, data gambar diam atau gerak, data animasi, suara, video dan atau gabungan dari semuanya, baik yang bersifat statis maupun dinamis. Saat ini terdapat beberapa platform untuk mempermudah pengguna dalam membangun sebuah website salah satunya adalah platform WordPress.

\section{Database MySQL}

Menurut Kadir [2] Database atau basis data merupakan suatu pengorganisasian sekumpulan data yang saling terkaitsehingga memudahkan aktivitas untuk memperoleh informasi. Basis data dimaksudkan untuk mengatasi problem pada sistem yang memakai pendekatan berbasis berkas.

Menurut Winarno [3] MySQL adalah sebuah software database. MySQL merupakan tipe data relasional yang artinya MySQL menyimpan datanya dalam bentuk tabel-tabel yang saling berhubungan. Keuntungan menyimpan data di database adalah kemudahannya dalam penyimpanan dan menampilkan data karena dalam bentuk tabel.

\section{Library FPDF}

FPDF adalah kelas PHP yang memungkinkan untuk menghasilkan file PDF dengan PHP murni, artinya tanpa harus menginstall modul PHP tambahan dan tanpa menggunakan perpustakaan PDFlib (FPDF) [4].

\section{Penelitian Sebelumnya}

Penelitian ini dikembangkan berdasarkan beberapa referensi dari penelitian sebelumnya yang telah kumpulkan dari beberapa sumber yang terkait dengan penelitian ini. Beberapa penelitian tersebut antara lain :

Andrian dkk., (2014) melakukan penelitian tentang Pengembangan Sistem Penelitian dan Pengabdian Dosen Jurusan Ilmu Komputer. Pada penelitian ini menggunakan metode RUP (Rational Unfield Proses) dengan Requirement sistem ini mampu mengelola data dan menampilkan hasilnya dalam bentuk tabel dan grafik [5].

Sakethi dkk., (2015) melakukan penelitian Pengembangan Sistem Informasi Pendaftaran Beasiswa Peningkatan Preatasi Akademik (PPA) Jurusan Ilmu Komputer Fakultas Matematika Dan Ilmu Pengetahuan Alam. Dalam Sistem ini diterapkan dua metode sorting yaitu quick sort dan selection sort, Tujuan dari pelelitian ini adalah untuk mempermudah alur proses pendaftaran beasiswa PPA pada jurusan Ilmu Komputer FMIPA [6].

Asmarani dkk., (2012) tentang Sistem Informasi Dosen Penasehat Akademik Pada Fakultas Teknologi Informasi Unversitas Budi Luhur. Pada penelitian ini digunakan framework CodeIgniter untuk pengembangan websitenya. Sistem ini dikembangkan untuk mempermudah dosen PA dalam memberikan pelaporan mengenai perkembangan mahasiswa kepada pihak program studi. Fitur yang terdapat pada sistem informasi in 
antara lain, melihat data mahasiswa, status mahasiswa, jadwal mahasiswa serta melihat nilai mahasiswa bimbingan dari masing-masing dosen PA [7].

Rachmansyah (2017) tentang Pengembangan front-end Sistem informasi marketplace indoexplorer.id berbasis web. Pengembangan frontend sistem informasi marketplace ini dikembangkan untuk memberikan informasi mengenai jasa liburan yang disediakan sebuah penyedia jasa travel. Pengembangan sistem ini diimplementasikan dengan menggunakan metode Scrum [8].

\section{Metodelogi}

Tahapan Penelitian

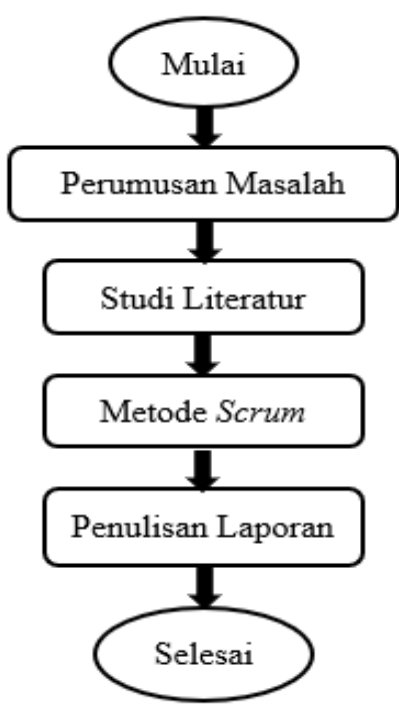

Gambar 1. Diagram Tahapan Penelitian.

\section{Perumusan Masalah}

Tahapan perumusan masalah dilakukan untuk merumuskan dan membatasi masalah yang diteliti dalam penelitian tersebut. Perumusan masalah ini diperlukan agar dalam pengembangan sistem ini lebih terarah dan tidak keluar dari batasan masalah yang telah ditentukan sebelumnya.

\section{Studi Literatur}

Tahapan studi literatur ini dilakukan untuk proses pencarian informasi yang dibutuhkan dalam pengembangan sistem pada penelitian ini mulai dari awal hingga akhir yang berguna untuk mengetahui yang dibutukan pada sistem. Hasil yang diperoleh pada tahapan ini berupa informasi yang dapat berupa teori-teori yang terkait dengan penelitian ini.

\section{Metode Scrum}

Penelitian ini menggunakan metode scrum, Metode scrum merupakan metode pengembangan perangkat lunak yang berfokus kepada strategi, fleksibilitas dan kecepatan dalam pengembangan sistem. Dalam pengembangannya akan dibagi menjadi unit-unit yang saling mendukung [9]. Tahapan pada metode scrum dilakukan dengan beberapa langkah yaitu pembuatan product backlog, sprint planning, daily scrum, sprint review, serta sprint retrospective [9].

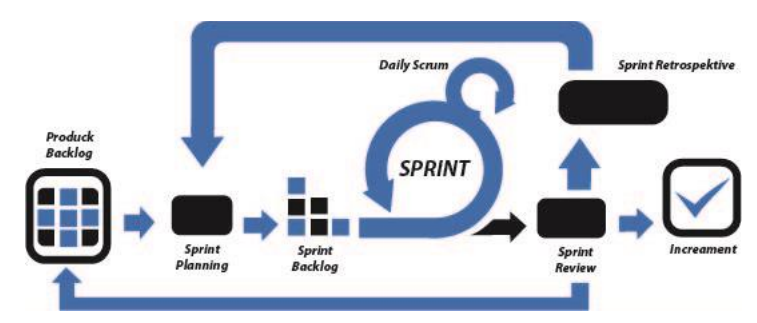

Gambar 2. Metode Scrum [9].

Tabel 1. Product Backlog Web Apps pada pengembangan SIMIPA

\begin{tabular}{|c|c|c|c|c|}
\hline No & $\begin{array}{l}\text { Sprint } \\
\text { Backlog }\end{array}$ & $\begin{array}{l}\text { Kesulit } \\
\text { an }\end{array}$ & $\begin{array}{l}\text { Estima } \\
\text { si } \\
\text { (hari) }\end{array}$ & $\begin{array}{l}\text { Spri } \\
n t \\
\text { ke- }\end{array}$ \\
\hline 1 & $\begin{array}{l}\text { Pembuatan } \\
\text { Use Case } \\
\text { Diagram }\end{array}$ & Rendah & 1 & 1 \\
\hline 2 & $\begin{array}{l}\text { Pembuatan } \\
\text { Activity } \\
\text { Diagram }\end{array}$ & Rendah & 1 & 1 \\
\hline 3 & $\begin{array}{l}\text { Pembuatan } \\
\text { Sequence } \\
\text { Diagram }\end{array}$ & Rendah & 1 & 1 \\
\hline 4 & $\begin{array}{l}\text { Form Layanan } \\
\text { - Status }\end{array}$ & Tinggi & 2 & 2 \\
\hline 5 & $\begin{array}{l}\text { Form Layanan } \\
\text { - Akademik }\end{array}$ & Tinggi & 2 & 2 \\
\hline 6 & $\begin{array}{l}\text { Form Layanan } \\
- \\
\text { Kemahasiswaa } \\
\mathrm{n}\end{array}$ & Sedang & 3 & 2 \\
\hline 7 & $\begin{array}{l}\text { Form } \\
\text { Layanan- } \\
\text { Umum dan } \\
\text { Keuangan }\end{array}$ & Sedang & 3 & 2 \\
\hline 8 & $\begin{array}{l}\text { Pengajuan } \\
\text { Layanan Baru }\end{array}$ & Tinggi & 2 & 3 \\
\hline 9 & $\begin{array}{l}\text { Layanan } \\
\text { Proses }\end{array}$ & Tinggi & 2 & 3 \\
\hline 10 & $\begin{array}{l}\text { Layanan } \\
\text { Selesai }\end{array}$ & Tinggi & 3 & 3 \\
\hline 11 & $\begin{array}{l}\text { Layanan } \\
\text { Ambil }\end{array}$ & Tinggi & 3 & 3 \\
\hline 12 & $\begin{array}{l}\text { Pengembanga } \\
\text { n Fungsi } \\
\text { Prestasi }\end{array}$ & Sedang & 3 & 4 \\
\hline 13 & $\begin{array}{l}\text { Pengembanga } \\
\text { n Fungsi Ubah } \\
\text { Profil }\end{array}$ & Sedang & 2 & 4 \\
\hline
\end{tabular}




\begin{tabular}{lllll}
\hline & & & & \\
\hline & Pengembanga & Tinggi & 3 & 4 \\
14 & n Fungsi & & & \\
Bimbingan & & & \\
& Draf & & & \\
\hline
\end{tabular}

Tabel 1. Product Backlog Web Apps pada pengembangan SIMIPA (Lanjutan)

\begin{tabular}{|c|c|c|c|c|}
\hline No & $\begin{array}{l}\text { Sprint } \\
\text { Backlog }\end{array}$ & $\begin{array}{l}\text { Kesulit } \\
\text { an }\end{array}$ & $\begin{array}{l}\text { Estima } \\
\text { si } \\
\text { (hari) }\end{array}$ & $\begin{array}{l}\text { Spri } \\
n t \\
\text { ke- }\end{array}$ \\
\hline 15 & $\begin{array}{l}\text { Pengembanga } \\
\text { n Fungsi } \\
\text { Detail } \\
\text { Bimbingan }\end{array}$ & Tinggi & 2 & 4 \\
\hline 16 & $\begin{array}{l}\text { Data Beasiswa } \\
\text { - Rekap }\end{array}$ & Tinggi & 4 & 5 \\
\hline 17 & $\begin{array}{l}\text { Daftar } \\
\text { Beasiswa }\end{array}$ & Tinggi & 4 & 5 \\
\hline 18 & $\begin{array}{l}\text { Kelola } \\
\text { Beasiswa } \\
\text { Aktif - Rekap }\end{array}$ & Tinggi & 2 & 6 \\
\hline 19 & $\begin{array}{l}\text { Pendaftar } \\
\text { Beasiswa - } \\
\text { Rekap }\end{array}$ & Tinggi & 3 & 6 \\
\hline 20 & $\begin{array}{l}\text { Penerima } \\
\text { beasiswa - } \\
\text { Rekap }\end{array}$ & Tinggi & 3 & 6 \\
\hline 21 & $\begin{array}{l}\text { Lembar } \\
\text { Penelitian - } \\
\text { Rekap }\end{array}$ & Tinggi & 3 & 7 \\
\hline 22 & $\begin{array}{l}\text { Lembar } \\
\text { Pengabdian - } \\
\text { Rekap }\end{array}$ & Tinggi & 3 & 7 \\
\hline 23 & $\begin{array}{l}\text { Lembar } \\
\text { Publikasi - } \\
\text { Rekap }\end{array}$ & Tinggi & 2 & 7 \\
\hline
\end{tabular}

\section{Penulisan Laporan}

Tahapan penulisan laporan ini dilakukan sebagai dokumentasi seluruh kegiatan pada seluruh tahapan penelitian yang dilakukan dari tahap awal sampai tahap akhir. Tahap penulisan laporan ini menjelaskan bagaimana penelitian ini berjalan dalam mengembangkan sebuah Sistem Informasi Terpadu Fakultas Matematika dan Ilmu Pengetahuan Alam.

\section{Hasil Dan Pembahasan}

Sistem Informasi Berbasis Web SIMIPA adalah sistem yang dikembangkan berdasarkan sistem yang sudah ada sebelumnya dan menambahkan beberapa fitur yang belum ada dengan tujuan untuk membantu proses pelayanan administrasi FMIPA agar terkelola secara sistematis. Pengembangan berfokus pada bagian front-end dan back-end website SIMIPA untuk mengelola data administrasi layanan yang dapat diakses mahasiswa, dosen serta staf FMIPA Universitas Lampung.

\section{Sprint ke-1}

\section{a. Sprint Planning}

Kegiatan dalam Sprint Planning pertama yang dilakukan adalah diskusi antara development team dan scrum master terkait rencana pengembangan SIMIPA. Pengembangan dimulai dengan merancang kebutuhan pada sistem dengan membuat rancangan alur sistem kedalam sebuah diagram sesuai dengan product backlog.

\section{b. Daily Sprint}

Pada tahap ini, tim scrum melakukan diskusi mengenai alur kerja sistem yang akan dikembangkan. Daily scrum berfokus untuk pembuatan diagram seperti usecase diagram, activity diagram dan sequence diagram. Proses pengerjaan berkoordinasi dengan semua anggota tim dalam pembuatannya agar dapat menghindari salah paham dalam proses bisnis pada aplikasi SIMIPA.

Usecase diagram pada SIMIPA memiliki 3 actor yaitu mahasiswa, dosen dan staf. Terdapat 7 usecase diagram pada keseluruhan pengembangan SIMIPA berbasis website, namun hanya 6 usecase yang akan dibahas pada penelitian ini dan usecase (warna merah pada Gambar 3) akan dibahas oleh tim developer website yang lain. Usecase diagram SIMIPA akan menggambarkan fungsi-fungsi yang tersedia pada website SIMIPA. Untuk lebih jelasnya dapat dilihat pada Gambar 3.

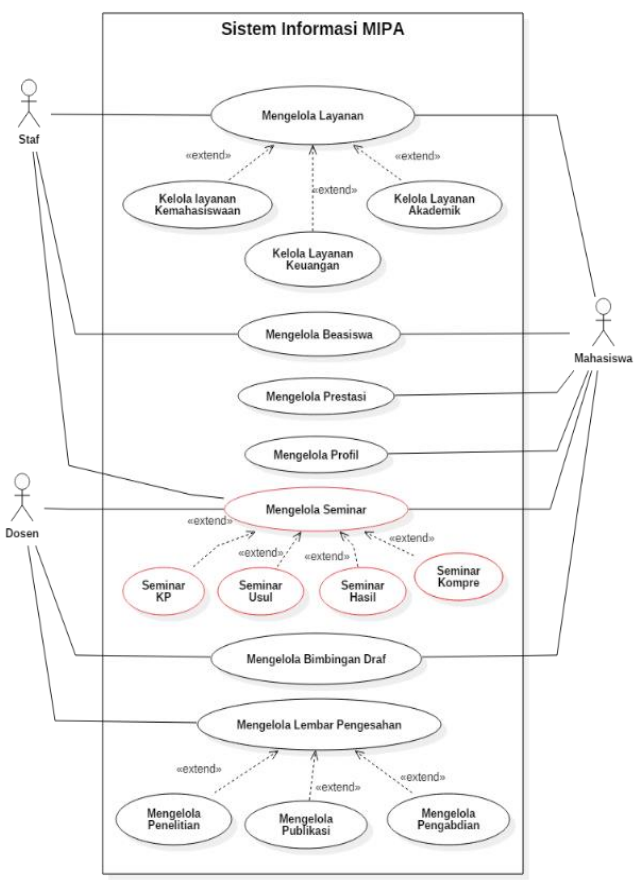


Gambar 3. Usecase Diagram.

\section{c. Sprint Review}

Pada tahap ini team kembali berkumpul dan melakukan diskusi membahas hal yang telah dilakukan pada sprint pertama. Setiap anggota development team akan mempresentasikan hasil pengerjaan sprint masing-masing. Pada SIMIPA akan memiliki 3 user yaitu mahasiswa, dosen, staf. User. Pada sprint pertama adalah melakukan perbaikan dengan melakukan penambahan relasi di setiap use case dengan relasi include/extend.

\section{d. Sprint Retrospective}

Sprint retrospective dilakukan setelah melakukan sprint review. Pada tahap ini seluruh tim Scrum berkumpul dan saling memberikan kritik serta saran mengenai hasil pengerjaan sprint pertama. Retrospective pada sprint pertama berjalan dengan dengan baik setalah melakukan perbaikan pada sprint review.

\section{Sprint ke-2}

\section{a. Sprint Planning}

Pada sprint planning ini, tim berfokus untuk mengembangan fungsi sistem SIMIPA modul mahasiswa pada bagian form layanan fakultas berdasarkan product backlog. Pengembangan dimulai dengan merancang fungsi-fungsi apa yang diharuskan ada pada menu agar sesuai dengan kebutuhan dari product backlog.

\section{b. Daily Sprint}

Daily sprint pada Sprint ke-2 adalah mengembangkan fitur pada product backlog dan mengimplementasikannya pada website SIMIPA. Output dari pengembangan layanan ini berupa berkas form layanan mahasiswa berekstensi PDF sebanyak 23 jenis form layanan akademik, 14 jenis form layanan kemahasiswaan serta 8 jenis form layanan umum dan keuangan. Hasil dari pengembangan fitur layanan dapat dilihat pada Gambar 4.

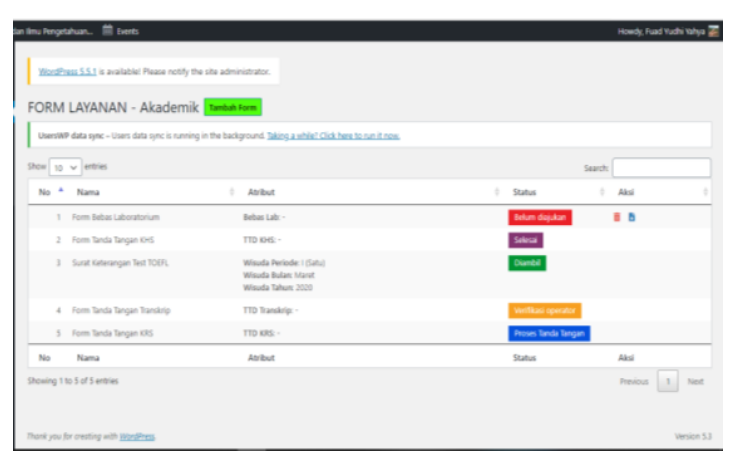

Gambar 4. Tampilan Menu Layanan.

\section{c. Sprint Review}

Seluruh tim berkumpul dan berdiskusi untuk membahas kegiatan yang telah dilakukan pada sprint 2. Tim development mempresentasikan hasil yang sudah dikerjakan selama kegiatan dalam daily sprint. Pada sprint ke-2 telah dilakukan pengujian fungsi sistem pada product backlog yang telah dikerjakan dengan hasil sesuai dengan fungsi yang diharapkan.

\section{d. Sprint Retrospective}

Pada sprint retrospective seluruh anggota tim berkumpul dan berdiskusi membahas masalah dan kendala yang dihadapi pada saat kegiatan daily sprint. Masalah yang dihadapi pada sprint 2 yaitu kesulitan dalam memahami proses bisnis administrasi form layanan FMIPA yang cukup banyak, Namun dapat terselesaikan dengan mendapat penjelasan langsung dari scrum master tentang proses bisnis administrasi layanan FMIPA.

Pengembangan fungsi layanan fakultas mahasiswa mendapat masukan dari scrum master untuk merubah tampilan verifikasi layanan pada berkas output file PDF dari semua layanan akademik, kemahasiswaan serta layanan umum dan keuangan.

\section{Sprint ke-3}

\section{a. Sprint Planning}

Sprint Planning berfokus untuk mengembangan fungsi sistem SIMIPA modul Staf administrasi pada bagian form layanan fakultas berdasarkan product backlog. Pengembangan dimulai dengan merancang fungsi-fungsi apa yang diharuskan ada pada menu agar sesuai dengan kebutuhan dari product backlog.

\section{b. Daily Sprint}

Daily sprint pada Sprint ke-3 adalah mengembangkan fitur pada product backlog dan mengimplementasikannya pada website SIMIPA. Output dari pengembangan layanan ini berupa sistem untuk memverifikasi form layanan yang masuk ke FMIPA.

Menu ini hanya dapat diakses oleh user SIMIPA dengan status sebagai staf administrasi, Fitur ini digunakan untuk memverifikasi form layanan yang masuk ke fakultas apakah benar bahwa data-data yang ada di form tersebut sesuai dengan data yang tersimpan di database SIMIPA. 


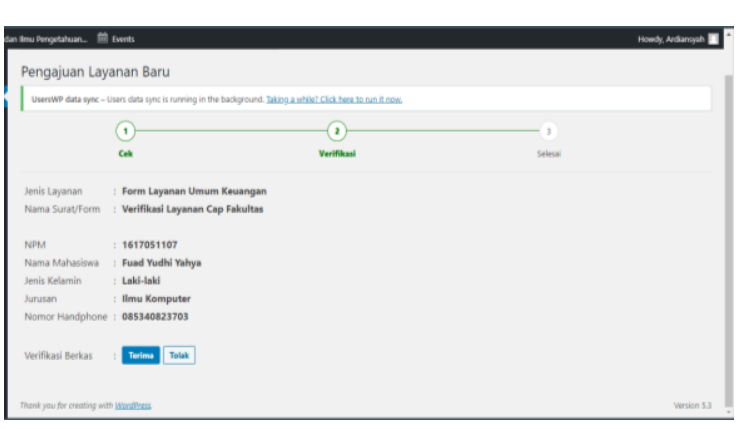

Gambar 5. Tampilan Menu Layanan Staf.

\section{c. Sprint Review}

Seluruh tim berkumpul dan berdiskusi untuk membahas kegiatan yang telah dilakukan pada sprint 3. Tim development mempresentasikan hasil yang sudah dikerjakan selama sprint 3 . Pengembangan fungsi verifikasi layanan fakultas untuk modul staf dianggap telah berfungsi dengan baik dan tidak mendapatkan masukan dari tim scrum.

\section{d. Sprint Retrospective}

Pada sprint retrospective seluruh anggota tim berkumpul dan berdiskusi membahas masalah dan kendala yang dihadapi pada saat kegiatan daily sprint. Tidak terdapat masalah yang berarti pada tahap pengembangan sprint ke 3, sehinga kegiatan dalam daily scrum berjalan dengan baik tanpa hambatan.

\section{Sprint ke-4}

\section{a. Sprint Planning}

Tahap Sprint Planning kali ini berfokus untuk mengembangan fungsi sistem SIMIPA modul mahasiswa pada bagian data prestasi, ubah profil mahasiswa, bimbingan draf untuk modul mahasiswa serta detail bimbingan draf untuk modul dosen berdasarkan product backlog. Pengembangan dimulai dengan merancang fungsi-fungsi apa yang diharuskan ada pada menu agar sesuai dengan kebutuhan dari product backlog.

\section{b. Daily Sprint}

Daily sprint pada Sprint ke-4 adalah mengembangkan fitur pada product backlog dan mengimplementasikannya pada website SIMIPA. Output dari pengembangan layanan ini berupa sistem yang menyimpan data profil mahasiswa, data prestasi mahasiswa, serta data bimbingan draf.

Menu Profil dapat digunakan user mahasiswa untuk merubah profil data diri seperti merubah foto profil, password, nama depan, nama akhir, alamat serta data diri yang lain sesuai dengan identitas mahasiswa tersebut.

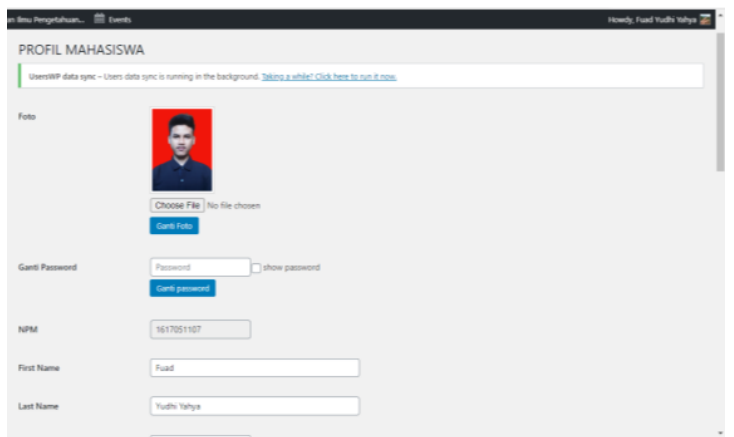

Gambar 6. Menu Profil.

Menu Prestasi merupakan fitur yang ada pada modul mahasiswa yang digunakan untuk merekap data prestasi yang diperoleh mahasiswa yang ada di ruang lingkup FMIPA Universitas Lampung. User mahasiwa dapat menambahkan prestasi yang telah diperoleh baik itu prestasi akademik maupun prestasi non-akademik. Informasi yang ditampilkan pada menu ini adalah jenis, tingkat, tahun nama kegiatan, penyelenggara kategori, capaian serta terdapat 3 aksi yang dapat user mahasiswa lakukan pada menu ini yaitu aksi tambah data, lihat sertifikat prestasi yang telah ditambahkan dan aksi hapus prestasi.

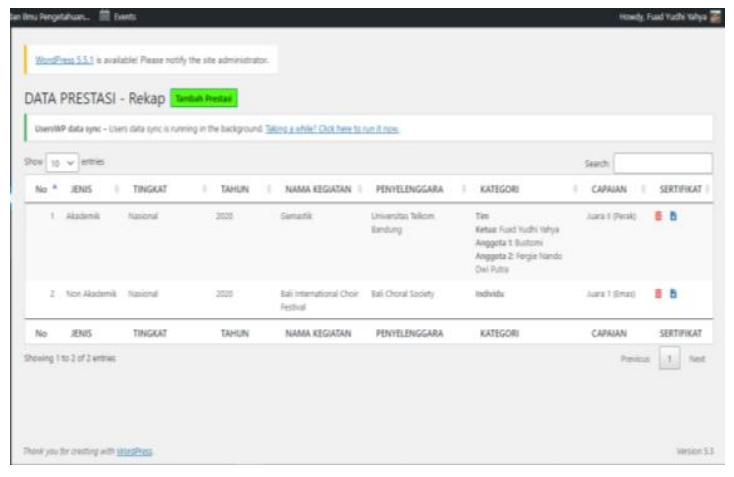

Gambar 7. Menu Prestasi.

Menu Bimbingan merupakan fitur yang ada pada modul mahasiswa yang digunakan untuk merekap data bimbingan setelah mahasiswa mengajukan tema penelitian. Data yang disimpan berupa tanggal kegiatan bimbingan, nama dosen pembimbing serta keterangan kegiatan bimbingan yang telah dilakukan. Pada menu ini terdapat aksi tambah data, edit data serta hapus data bimbingan. Sedangkan menu bimbingan pada modul dosen menampilkan data yang telah diisi oleh mahasiswa bimbingan. 


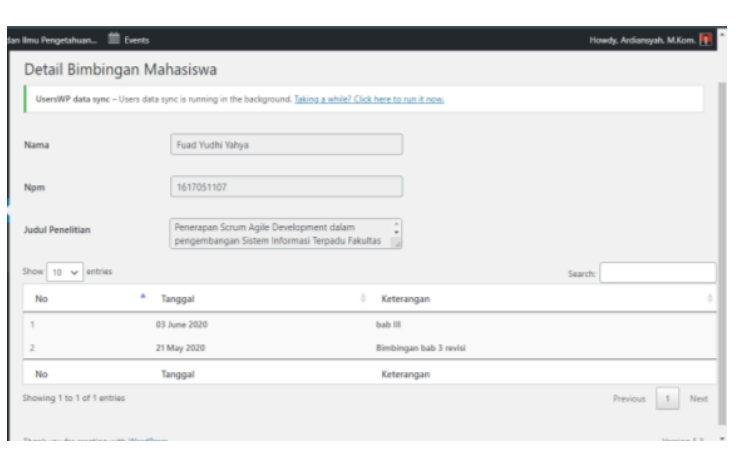

Gambar 8. Menu Bimbingan.

\section{c. Sprint Review}

Pada Sprint Review ke-3, pengembangan sistem mendapatkan saran dan masukan dari tim scrum pada menu tambah data prestasi agar pada saat menambahkan data kelompok atau anggota tim dapat dilakukan secara dinamis serta anggota tim yang dapat ditambahkan hanya mahasiswa FMIPA Universitas Lampung. Selain itu terdapat perubahan product backlog yang sebelumnya ada 6 menjadi 4 product backlog dengan menghilangkan fitur menu perkuliahan modul dosen serta menu perkuliahan pada modul mahasiswa yang dianggap tidak dibutuhkan lagi karena fitur tersebut sudah ada pada sistem siakadu Universitas Lampung.

\section{d. Sprint Retrospective}

Pada sprint retrospective ke-4, masukan dan saran dari tim scrum yang diperoleh dari sprint review dikerjakan pada sprint retrospective. Selain itu seluruh anggota tim berkumpul dan berdiskusi membahas masalah dan kendala yang dihadapi dan menyampaikan solusinya masing-masing pada sprint 4. Sprint 4 selesai karena setelah sprint review dilakukan, tim pengembang, scrum master, ataupun product owner telah menyetujui hasil product backlog yang telah dikerjakan, sehingga dapat melanjutkan pada sprint ke -5 .

\section{Sprint ke-5}

\section{a. Sprint Planning}

Perencanaan kegiatan pada Sprint Planning berfokus untuk mengembangan fungsi sistem SIMIPA modul mahasiswa pada fitur beasiswa berdasarkan product backlog yang telah dibuat. Pengembangan dimulai dengan merancang fungsifungsi ada pada menu agar sesuai dengan kebutuhan dari product backlog.

\section{b. Daily Sprint}

Daily sprint pada Sprint ke-5 adalah mengembangkan fitur pada product backlog dan mengimplementasikannya pada website SIMIPA. Output dari pengembangan layanan ini berupa sistem yang berfungsi untuk membantu mempermudah mahasiswa untuk mendapat informasi tentang pendaftaran beasiswa.

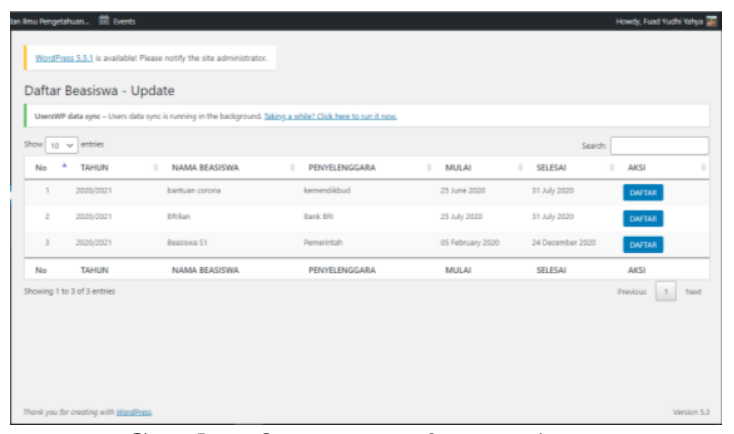

Gambar 9. Menu Dafar Beasiswa.

\section{c. Sprint Review}

Seluruh tim berkumpul dan berdiskusi untuk membahas kegiatan yang telah dilakukan pada sprint 5. Tim development mempresentasikan hasil yang sudah dikerjakan selama sprint 5. Pengembangan fungsi beasiswa untuk modul mahasiswa dianggap telah berfungsi dengan baik dan tidak mendapatkan masukan dari tim scrum.

\section{d. Sprint Retrospective}

Pada tahap ini, seluruh anggota tim berkumpul dan berdiskusi membahas masalah dan kendala yang dihadapi pada saat kegiatan daily sprint. Tidak terdapat masalah yang berarti pada tahap pengembangan sprint ke 5, sehinga kegiatan dalam daily scrum berjalan dengan baik tanpa hambatan.

\section{Sprint ke-6}

\section{a. Sprint Planning}

Fokus utama pada Sprint Planning kali ini adalah untuk mengembangan fungsi sistem SIMIPA modul staf pada fitur beasiswa berdasarkan product backlog yang telah dipaparkan pada Bab 3 sebelumnya. Pengembangan dimulai dengan merancang fungsi-fungsi ada pada menu agar sesuai dengan kebutuhan dari product backlog.

\section{b. Daily Sprint}

Daily sprint pada Sprint ke-6 adalah mengembangkan fitur pada product backlog dan mengimplementasikannya pada website SIMIPA. Output dari pengembangan layanan ini berupa sistem yang berfungsi untuk mengelola data beasiswa yang ada di FMIPA Universitas Lampung. 


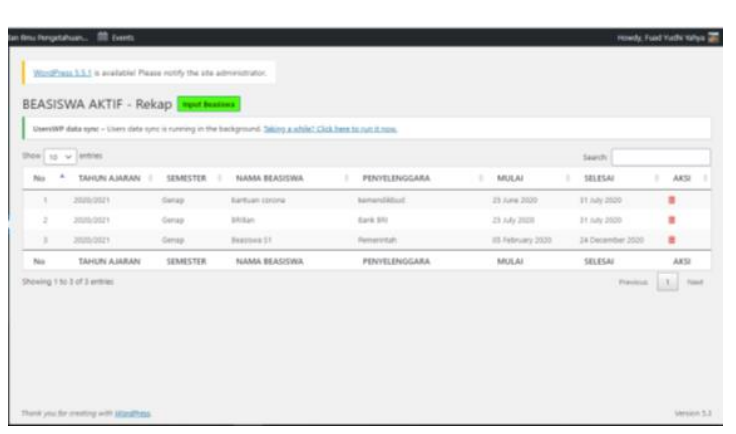

Gambar 10. Menu Kelola Beasiswa.

\section{c. Sprint Review}

Seluruh tim berkumpul dan berdiskusi membahas kegiatan yang telah dilakukan pada sprint 6 . Tim development mempresentasikan hasil yang sudah dikerjakan selama sprint 6 . Pengembangan fungsi beasiswa untuk modul staf mendapatkan masukan dari tim scrum pada bagian jenis berkas persyaratan dibuatkan menu terpisah agar user staf dapat menambahkan jenis berkas persyaratan secara dinamis

\section{d. Sprint Retrospective}

Pada sprint retrospective ini, seluruh anggota tim berkumpul dan berdiskusi membahas masalah dan kendala yang dihadapi pada saat kegiatan daily sprint. Masalah yang dihadapi pada sprint 6 yaitu bagaimana cara user staf dapat menambahkan jenis berkas persyaratan secara dinamis. Masalah tersebut dapat terselesaikan dengan mendapat masukan dari tim scrum untuk menambahkan menu atau fitur baru untuk menabahkan jenis berkas persyaratan secara dinamis.

\section{Sprint ke-7}

\section{a. Sprint Planning}

Sprint Planning pada sprint terakhir ini difokuskan untuk mengembangan fungsi sistem SIMIPA modul dosen pada fitur layanan lembar pengesahan berdasarkan product backlog. Pengembangan dimulai dengan merancang fungsifungsi ada pada menu agar sesuai dengan kebutuhan dari product backlog.

\section{b. Daily Sprint}

Daily sprint pada Sprint ke-7 adalah mengembangkan fitur pada product backlog dan mengimplementasikannya pada website SIMIPA. Output dari pengembangan layanan ini berupa sistem yang menyimpan data form layanan penelitian, pengabdian, serta data form layanan publikasi.

Menu Penelitian menampilkan informasi tentang rekap lembar penelitian yang telah diambil oleh user dosen. Pada menu ini terdapat 5 aksi yang dapa user dosen lakukan yaitu tambah data penelitian baru, ubah data penelitian, hapus data penelitian, lihat detail penelitian serta unduh lembar penelitian.

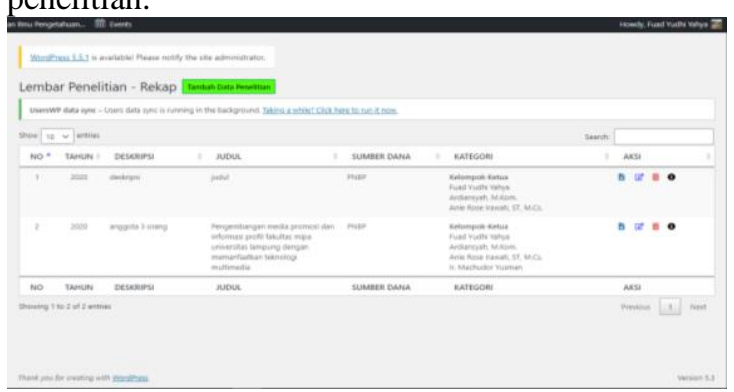

Gambar 11. Menu Penelitian.

Menu ini menampilkan informasi tentang rekap lembar pengabdian yang telah diambil oleh user dosen. Pada menu ini terdapat 5 aksi yang dapa user dosen lakukan yaitu : tambah data pengabdian baru, ubah data pengabdian, hapus data pengabdian, lihat detail pengabdian serta unduh lembar pengabdian.

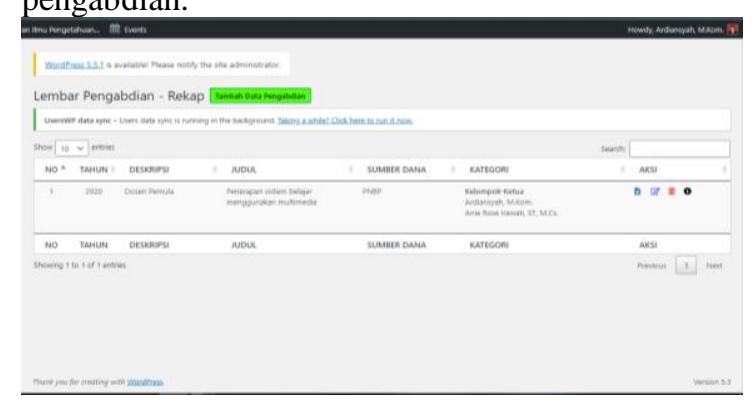

Gambar 12. Menu Pengabdian.

Menu ini menampilkan informasi tentang rekap lembar publikasi yang telah diambil oleh user dosen. Pada menu ini terdapat 5 aksi yang dapa user dosen lakukan yaitu : tambah data publikasi baru, ubah data publikasi, hapus data publikasi, lihat detail publikasi serta unduh lembar publikasi.

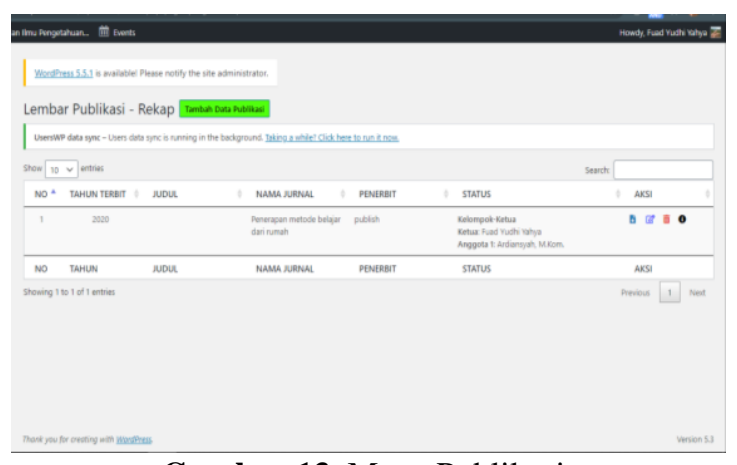

Gambar 13. Menu Publikasi.

\section{c. Sprint Review}

Seluruh tim berkumpul dan berdiskusi membahas kegiatan yang telah dilakukan pada sprint 5. Tim development mempresentasikan hasil yang sudah dikerjakan selama sprint 5 . Pengembangan fungsi pengesahan mendapatkan masukan dari tim scrum pada bagian fitur 
pengesahan Pada menu pengesahan rekap sebaiknya dibuat rekap pengesahan berdasarkan jenis pengesahan dan tahun.

\section{d. Sprint Retrospective}

Pada sprint retrospective ini, seluruh anggota tim berkumpul dan berdiskusi membahas masalah dan kendala yang dihadapi pada saat kegiatan daily sprint. Pengembangan sistem pada sprint ke-7 terdapat kendala pada pengembangan menu pengesahan rekap dimana data belum dapat diurutkan berdasarkan tahun, sehingga data hanya diurutkan berdasarkan jenis pengesahan untuk mengatasi masalah tersebut.

\subsection{Pengujian}

Pengujian sistem dilakukan menggunakan metode blackbox testing yang berfokus pada persyaratan fungsional perangkat lunak [10]. Pengujian ini berusaha menemukan kesalahan dalam kategori fungsi - fungsi yang tidak benar atau hilang, kesalahan interface, kesalahan dalam struktur data atau akses database eksternal, serta kesalahan kinerja. Pengujian dilakukan oleh internal tim scrum pada saat kegiatan sprint review dimasing-masing sprint.

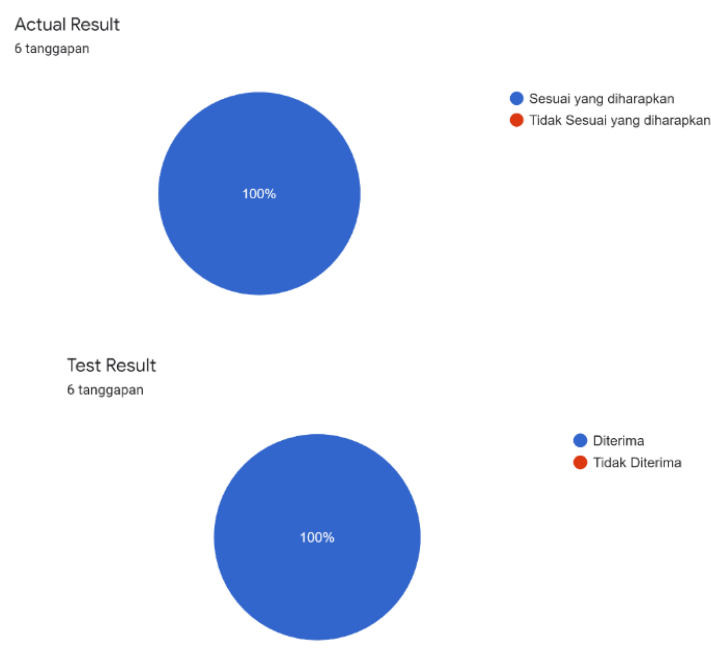

Gambar 14. Diagram Hasil Pengujian sistem.

\section{Kesimpulan}

Sistem Informasi Fakultas Matematika dan Ilmu Pengetahuan Alam (SIMIPA) berhasil dikembangkan dengan menggunakan metode scrum. Penelitian ini dilakukan berdasarkan tahapan scrum dengan sprint sebanyak 7 iterasi. Jumlah product backlog pada tim web apps yang dibuat oleh product owner terdapat 23 item. Hasil dari penelitian ini berupa sebuah website SIMIPA yang digunakan sebagai sistem layanan administrasi yang ada di FMIPA.
Pengujian sistem telah dilakukan untuk menguji fungsionalitas dan berhasil karena semua fungsional berjalan sesuai output yang diinginkan. Data diri yang ada pada database sudah dimanfaatkan untuk mengisi form layanan pada fakultas dan mahasiswa sudah dapat melihat tracking form layanan yang telah di ajukan secara real time pada fitur form layanan. Beberapa fitur dalam penelitian ini sudah digunakan oleh mahasiswa FMIPA Universitas Lampung untuk keperluan administrasi di lingkup FMIPA.

\section{DAFTAR PUSTAKA}

[1] Jogiyanto, H. 2010. Analisis dan Desain Sistem Informasi, Edisi III. Yogyakarta: Andi Offset.

[2] Kadir, A. 2014. Pengenalan Sistem Informasi. Yogyakarta: Andi Offset.

[3] Winarno, E., dan Ali Zaki, S. 2014. Pemrograman Web Berbasis HTML5,. Jakarta: PT Elex Media Komputindo.

[4] FPDF. 2020. Documentation and download FPDF. Online at http://www.fpdf.org/ diakses 30 September 2020

[5] Andrian, R., Sakethi, D., dan Chairuddin, M. 2014. Pengembangan Sistem Informasi Penelitian dan Pengabdian Dosen. Jurnal Komputasi Ilmu Komputer Unila, 1-5.

[6] Sakethi, D., Febriansyah, F. E., dan Sari, N. 2015. Pengembangan Sistem Informasi Pendaftaran Beasiswa PPA. Jurnal Komputasi Ilmu Komputer Unila, 1-3.

[7] Asmarani, B. D., Kalvinly, Putra, P. U., dan Rony, M. A. 2012. Sistem Informasi Dosen Penasehat Akademik. Semantik, 1-3.

[8] Rachmansyah, I. 2017. Pengembangan Frontend Sistem Informasi Marketplace Inoexplorer.id berbasis web. IPB, 1-5.

[9] P. A. G. Permana. 2015. Scrum Method Implementation in a Software Development Project Management, International Journal of Advanced Computer Science and Applications, vol. 6, no. 9, pp. 198-204.

[10] Mustaqbal, Sidi, M., Firdaus, R., \& Rahmadi, H. 2015. Pengujian Aplikasi Menggunakan Black Box Testing Boundary Value Analysis (Studi Kasus: Aplikasi Prediksi Kelulusan SNMPTN). Jurnal Ilmiah Teknologi Informasi Terapan 1 (3), 31-36. 